\title{
O AUTORITARISMO NO BRASIL: LIMITES E ALCANCE DA NOSSA EXPERIENCIA DEMOCRÁTICA
}

\author{
Sandra Maciel-Lima ${ }^{1}$ \\ José Edmilson de Souza-Lima ${ }^{2}$ \\ Chantal Correia de Castro ${ }^{3}$
}

\section{RESUMO}

Estamos em choque diante da ascensão do autoritarismo ao redor do mundo, mas seguimos elegendo políticos com estas características - por que então ficamos surpresos? Apontar o dedo para as atrocidades cometidas por políticos autoritários parece ser mais fácil do que olhar-se no espelho. Por meio da análise de diferentes obras sobre o tema do autoritarismo, tiramos o foco dos políticos para compreender as tendências autoritárias do povo brasileiro. Entender por que permitimos o retorno do autoritarismo é fundamental para entender os limites e alcance da nossa experiência democrática. se a nossa democracia tem salvação. [Só o brasileiro pode mudar o curso da sua própria história, basta ele querer fazê-lo .

Palavras-chave: Política; Mandonismo; Elite

\begin{abstract}
We are all shocked by the rise of the authoritarianism around the world, but we keep on electing politicians with these features - why then are we so surprised? Pointing the finger to the horrors committed by these authoritarian leaders is easier than taking a look in the mirror. By means of analyzing different studies regarding the authoritarian issue, we take the focus off the politicians to understand the authoritarian tendencies of the Brazilian people. Realize why we allowed the return of authoritarianism is central to understanding if our democracy can be saved.
\end{abstract}

Keywords: Politics; Authoritarianism; Elite

\footnotetext{
${ }^{1}$ Pesquisadora e Docente do Programa de Pós-Graduação em Direito Empresarial e Cidadania do Centro Universitário Curitiba. E-mail: maciellima.sandra@gmail.com

${ }^{2}$ Pesquisador e Docente do Programa de Pós-Graduação em Direito Empresarial e Cidadania do Centro Universitário Curitiba. E-mail: zecaed@hotmail.com

${ }^{3}$ Mestranda do Programa de pós-graduação em Direito empresarial e Cidadania - UNICURITIBA. Advogada pós-graduada em Direito dos Contratos pela FGV Law e especialista em Direito Internacional Público pela The Hague Academy.
} 


\section{INTRODUÇÃO}

O ano é o de 2020, o século é o XXI e o tema que tem dominado os debates políticos em todo o mundo é o autoritarismo. Parece uma piada de mau gosto, mas é verdade. Uma espécie de arena autoritária internacional vem sendo construída nos últimos anos em contraponto ao mundo liberal que prevaleceu no pós-Segunda Guerra Mundial (INSTITUT MONTAIGNE, 2018). Candidatos estão mais agressivos, sistemas eleitorais estão mais voláteis e eleitores estão mais hostis às normas e instituições democráticas.

Alguns defendem que a razão para o atual descontentamento político é econômica, enquanto outros entendem que é cultural ou geracional, de uma forma ou de outra, como é possível que décadas de luta pela democracia e pela garantia de direitos fundamentais tenham nos trazido a este ponto: o renascimento do autoritarismo?

O mundo liberal está, de fato, em crise. De acordo com o relatório Democracy Index 2019 existem no mundo hoje 54 regimes autoritários, o que representa um terço dos países do globo. O número é superior ao número de democracias plenas (22 países) e igual ao número de democracias com falhas (54 países), restando ainda 37 países governados por regimes híbridos (THE ECONOMIST INTELLIGENCE UNIT, 2020). Algumas das maiores potências mundiais, como China, Rússia e Turquia, já seguem a tendência política autoritária enquanto outras, historicamente democráticas, como Brasil e Estados Unidos, vêm trilhando o mesmo caminho, mas por que isso aconteceu? A democracia deixou de ser considerada a melhor forma de governo?

O ressentimento com a democracia liberal além de poder ser sentido em todos os cantos do globo, extrapolou a polarização ideológica de esquerda e direita no espectro político que parece ter perdido o sentido. A divisão se dá hoje entre os que defendem liberalismo e democracia, de um lado, e conservadorismo e autoritarismo, do outro. Nesta mesma linha, David Adler (2018) concluiu em um artigo do The New York Times que em muitos países desenvolvidos os maiores críticos à democracia e os mais favoráveis ao autoritarismo são os eleitores de centro. Segundo o cientista político ao mesmo tempo em que as democracias ocidentais tornam-se disfuncionais, nenhum grupo está imune ao fascínio do autoritarismo, menos ainda os centristas, que preferem um governo forte e eficiente no lugar da bagunçada política democrática (ADLER, 2018).

De toda forma, desde os anos 1930 não testemunhávamos um processo tão forte de radicalização social e de descaso com as instituições democráticas. O cidadão nunca esteve menos comprometido com a democracia nem mais receptivo às alternativas despóticas. 
Passamos a acreditar que o autoritarismo e o endurecimento das práticas liberais são a melhor solução para o nosso futuro, mas por quê? Os líderes autoritários assumiram o governo de diversos países, mas eles não o fizeram por meio de golpes e revoluções, mas sim com o apoio e o voto dos seus eleitores. Então por que nós os estamos colocando no poder?

Para o caso brasileiro, são essas perguntas que a historiadora e antropóloga Lilia Moritz Schwarcz buscou responder por meio do seu livro "Sobre o Autoritarismo Brasileiro" (2019). A professora da USP, mesmo sem fazer referencia direta à eleição do presidente do Brasil, busca entender porque o brasileiro flerta com o autoritarismo mesmo depois de décadas de regime democrático; como nossa bagagem histórica serve para explicar o momento em que vivemos hoje e o que precisamos fazer se quisermos mudar os rumos da nossa politica.

Com base neste livro e em outras obras sobre o tema, este artigo igualmente busca tirar o foco dos políticos para analisar o comportamento dos eleitores, acreditando que seja mais útil entender a causa e não a consequência do problema autoritário. Procuramos, portanto, abordar o tema do autoritarismo sob a ótica do eleitor e não do político brasileiro. $\mathrm{Na}$ balança entre a democracia liberal e o autoritarismo para que lado pende o Brasil?

\section{As características do autoritarismo (nos políticos e nos seus eleitores)}

Vivendo por anos sob a hegemonia da democracia liberal, tínhamos a certeza de que os grandes traumas da história não mais retornariam e que nazismo, fascismo e comunismo tinham ficado no passado. Porém, desde o final da Guerra Fria não presenciávamos tendências autoritárias tão intensas e o retorno de características dos regimes mundiais mais desagradáveis "uma mistura de ditadores, homens fortes e governos autoritários" (DOBSON, 2013, p. 4).

Até pouco tempo, a democracia liberal reinava absoluta. A despeito de todas as suas deficiências, a maioria dos cidadãos parecia profundamente comprometida com a sua forma de governo. A economia estava em crescimento. Os partidos radicais eram insignificantes. Os cientistas políticos achavam que em lugares como a França ou os Estados Unidos a democracia chegara para ficar fazia um bom tempo e que em anos vindouros pouca coisa mudaria. Politicamente falando, assim parecia, o futuro não seria muito diferente do passado. Então o futuro chegou - e se revelou, na verdade, bem diferente. (MOUNK, 2019, n.p.)

Diante de uma recessão democrática, os maiores beneficiados são os governantes que endossam um pensamento autoritário. Em meio ao caos e à instabilidade, os populistas 
enchem a população de falsas promessas baseadas em um passado glorioso e posam de heróis, tomando para si o dever de salvar a pátria. Orbán, Erdogan, Xi Jinping, Netanyahu, Bolsonaro, Duerte, Maduro, bin Salman, Putin e Trump foram alguns dos líderes que foram apelidados de "neo-autoritários" pelo think tank francês Institut Montaigne (2018). Não importa se se trata de um ditador comunista, de um líder honesto eleito graças a sua oposição ao sistema vigente ou de um príncipe árabe buscando encontrar os limites do seu poder, todos chegaram ao poder defendendo a xenofobia, o ultranacionalismo e o sentimento antiestablishment (INSTITUT MONTAIGNE, 2018).

Naturalizar a desigualdade e evadir-se do passado é característico de governos autoritários que, não raro, lançam mão de narrativas edulcoradas como forma de promoção do Estado e de manutenção do poder. Mas é também fórmula aplicada, com relativo sucesso, entre nós, brasileiros. (SCHWARCZ, 2019, p. 19)

A Rússia, a China e até a Venezuela são exemplos deste novo autoritarismo ou do totalitarismo sofisticado, não há mais que se falar em totalitarismo a la Coréia do Norte. Nos sistemas autoritários modernos existe "oposição", o Congresso permanece aberto e a mídia funciona, mas tudo dentro de um determinado limite, tudo é controlado. Seus comandantes são escolados em gerar percepções falsas e muito competentes em cercar-se de aliados, eles já entenderam que precisam utilizar-se de algumas prerrogativas democráticas para perpetuarem-se no poder. Levitsky e Ziblatt (2018, p. 19) defendem que "o paradoxo trágico da via eleitoral para o autoritarismo é que os assassinos da democracia usam as próprias instituições da democracia - gradual, sutil e mesmo legalmente para matá-la”. Os neoautocratas sabem que mais vale fraudar os resultados de uma eleição do que suspendê-la por completo, é melhor manter o parlamento funcionando e comprar o voto dos seus membros do que fechá-lo.

Portanto, concluem Levitsky e Ziblatt (2018, p. 108) que "uma das grandes ironias de como as democracias morrem é que a própria defesa da democracia é muitas vezes usada como pretexto para a sua subversão" Atualmente as democracias não são atacadas de fora, elas acabam padecendo por dentro. São os eleitores que colocam o poder na mão dos políticos de forma legítima e pacífica, sem boicotes, enfrentamentos ou violência. $\mathrm{O}$ voto popular torna-se a melhor arma para usurpar o poder.

Se para chegarem ao poder os políticos autoritários dependem de eleições, são as vontades e expectativas de seus eleitores que precisam ser compreendidas. $\mathrm{O}$ autoritarismo seria um atributo do eleitor e não do político, que nem precisaria necessariamente ser 
arbitrário para conseguir implantar com sucesso uma retórica opressiva e atrair seguidores (STENNER; HAIDT, 2018).

Ao analisarmos a sociedade, portanto, entendemos que a democracia liberal nos levou a alcançar grandes patamares de diversidade social e cultural e nos garantiu um maior rol de liberdades individuais. No setor econômico e político, o mundo globalizado nos colocou em contato com outras realidades e desafios. Hoje conhecemos mais, podemos mais e temos mais acesso a tudo o que acontece no mundo. Este mar de possibilidades tornam nossas vidas mais dinâmicas e complexas, mas o que para a maioria das pessoas pode soar positivo, em outras causa insegurança e ansiedade.

A incerteza quanto ao próprio futuro, somada a uma rápida transformação social e a uma estagnação econômica podem ter sido o gatilho para desejo do retorno de viés autoritário na política. Quanto maior a sensação de falta de controle sobre o mundo e a sua realidade, maior é a busca de algumas pessoas por algo (ou alguém) que lhes assegure a ordem e privilegie o conhecido, papel que passa a ser cumpridos pelos políticos autoritários. Como defende Lilia Schwarcz (2019, p. 231) “o vazio social e o ceticismo adubaram um terreno já fértil para a ascensão de pretensos outsiders, políticos autoritários, oportunistas e populistas".

O cansaço [em relação ao crescimento da criminalidade, da deterioração da segurança pública, da recessão e da corrupção] por sua vez, deu vazão ao ressentimento e à manifestação direta de valores conservadores, no sentido de quem quer "conservar" mesmo, e que mudaram o que parecia ser uma utopia partilhada na forma de entender, preservar e ampliar direitos. (SCHWARCZ, 2019, p. 216)

O populismo que vemos hoje é muito mais o reflexo de uma reclamação acerca do atual estado do mundo (uma percepção das condições contemporâneas), uma demanda por menos diversidade social e por um governo menos "politicamente correto", do que uma visão de vida ideal (STENNER; HAIDT, 2018). O fato de não estarmos progredindo economicamente, de não termos conseguido combater a violência e a desigualdade, de acolhermos as mais diversas manifestações sociais e culturais faz com que algumas pessoas preferissem o retorno a uma ordem anterior onde reinava a suposta "normalidade" e estabilidade. A parcela da população com visão antidemocrática não tolera o sistema "politicamente correto" que, a seu ver, perdeu o contato com aqueles que representa (STENNER; HAIDT, 2018). Nos Estados Unidos, por exemplo, país considerado um pilar da democracia moderna, a preferência por um líder forte é a maior em vinte anos (MOUNK, 2019). 
Os indivíduos com fortes tendências autoritárias gostam de obediência e de hierarquia e buscarão "homens fortes" para combater as mudanças que acabam levando a uma quebra de paradigmas diante do crescimento da liberdade e da diversidade. Quando perguntados sobre quais qualidades devem ser encorajadas em crianças, as pessoas com disposições autoritárias tendem a priorizar a subordinação, as boas maneiras e o bom comportamento no lugar da independência, da curiosidade e da autenticidade (STENNER; HAIDT, 2018).

$\mathrm{O}$ autoritarismo seria, portanto, determinado por uma falta de tolerância às novas experiências, uma reduzida capacidade do indivíduo de suportar complexidade, diversidade e diferença (STENNER; HAIDT, 2018). Diferente do conservadorismo, o autoritarismo não seria conduzido como uma aversão à mudança, mas por uma intolerância à complexidade (STENNER; HAIDT, 2018). O autoritário, diferente do conservador, irá sacrificar o status quo e abandonar autoridades e normas postas quando estas não mais servirem para cumprir o seu objetivo principal que é o de alcançar uniformidade e minimizar as diferenças (STENNER, 2005). Somente quando a preservação do status quo servir para promover a unidade e limitar a diversidade é que os autoritários serão conservadores no sentido de resistir mudanças.

Muito mais do que um desgosto pela diferença, o autoritarismo se torna uma visão de mundo em que mais vale a obediência e a conformidade do que a liberdade e a autonomia (STENNER, 2005). Para alcançar esta visão de mundo, os autoritários recorrem a forças políticas que limitem o comportamento da população, acarretando em discriminação e restrições contra minorias, limitações à liberdade de expressão e de reunião, entre outros.

O fortalecimento da unidade e a minimização da diversidade, o retorno a valores ultrapassados e o abandono das liberdades conquistadas, requerem domínio e limitação e só conseguem ser impostos a uma sociedade diversa e plural por meio da força. Unidade e uniformidade só são alcançadas por meio de um controle coercivo. Buscando obediência e conformidade, voluntariamente ou não, escolhemos seguir o caminho autoritário, o qual não esperávamos ter que fazer novamente (MOUNK, 2019).

É assim que a crise de legitimidade democrática foi gerando um discurso do medo e uma prática política que propõe voltar ao início. Voltar ao Estado como centro da decisão, acima das oligarquias econômicas e das redes globais. Voltar à nação como comunidade cultural da qual são excluídos os que não compartilham valores definidos como originários. (CASTELLS, 2018, n.p)

Em outro estudo, Kakkar e Sivanathan (2017) apontam que, em momentos de crise, 
mesmo podendo eleger um candidato respeitado e de boa reputação, a população tende a optar pelo político com tendências mais dominantes. Ao contrário de um líder exemplar, admirado e respeitado, eleito com base no seu prestígio e que governará com generosidade e diplomacia para resolver um problema, o governante autoritário estará disposto a passar por cima de tudo e de todos para alcançar o seu objetivo e é isso que gera confiança e cativa a muitos (KAKKAR; SIVANATHAN, 2017). O líder dominante com personalidade assertiva, controladora e confiante, mesmo que narcisista, agressivo e imoral, seria, portanto, uma resposta necessária e compensadora para restaurar a normalidade e a ordem em momentos difíceis, (KAKKAR; SIVANATHAN, 2017).

(...) a maioria dos partidários dos populistas tem plena consciência de que seu líder mente, dissemina mensagens de ódio e não passa de um bronco. Convencidos de que os políticos tradicionais nada têm a lhes oferecer é precisamente isso que os atrai nele. Sempre existe a chance, dizem a si mesmos, de que o populista realize uma fração de suas promessas irreais. E, pelo menos, ele vai poupá-los da hipocrisia envaidecida da velha-guarda. (MOUNK, 2019, n.p)

Neste sentido, é indispensável constatar que o fenômeno antidemocrático e os indivíduos com tendências autoritárias não são contra qualquer tipo de político ou qualquer sistema político - não se assemelham a uma anarquia, mas a um regime forte. Eles não rejeitam todas as instituições governamentais, muito pelo contrário, só rejeitam a forma como a política é feita hoje - de forma democrática e liberal. Os autoritários são, de fato, os mais propensos a ceder parte de sua liberdade a governos e governantes e os primeiros a defender a existência e leis e instituições rígidas, desde que sejam eficazes ao defender e manter a ordem (KAKKAR; SIVANATHAN, 2017).

\section{2. $\mathrm{O}$ caso brasileiro}

Se a saúde da democracia é medida pela robustez de suas instituições, no Brasil, onde elas são dominadas por interesses da elite no poder desde os tempos coloniais, o seu estado é grave. Apesar de a democracia exigir constante vigilância e ser, fundamentalmente, um processo inconcluso segundo Schwarcz (2019), no Brasil estamos especialmente atrasados.

Para a autora não é coincidência que nos últimos anos tenhamos iniciado um acentuado processo de radicalização social no Brasil, com crescente descaso e pouco 
comprometimento com as instituições democráticas, os partidos e a política (SCHWARCZ, 2019). Diante de um cenário de aceitação de uma maior diversidade social, de recessão econômica e de polarização política, a sociedade se dividiu e um dos lados passou a acolher a retórica autoritária.

Acontece que no Brasil o autoritarismo é substancialmente hereditário (STENNER; HAIDT, 2018) e nossa raiz autoritária persiste apesar de já termos passado por diversas mudanças políticas. Para entender o porquê precisamos voltar no tempo. A história do Brasil é bastante particular, pelo seu tamanho continental e seu povo miscigenado. Perceber suas peculiaridades é fundamental para entendermos porque agimos como agimos e elegemos quem elegemos.

É justamente a falta de vivência e de conhecimento sobre a história que leva os jovens a tornarem-se especialmente críticos à democracia. Esta parcela da população que nasceu e viveu toda a sua vida sob um regime democrático tem pouca noção do que seja experimentar um regime autoritário com privação de direitos. De fato, é mais fácil apontar o dedo para os políticos e seus vieses autoritários, sua ganância pelo poder e seu comportamento corrupto do que vasculhar a questão mais a fundo.

Se os candidatos eleitos não são mais do que a consequência e não a causa da atual ascensão autoritária. Se o povo (ainda) elege os seus políticos, porque estamos colocando governantes despóticos no poder? Entender o crescimento do autoritarismo por meio de um estudo aprofundado da história de um povo é, sem dúvidas, o melhor caminho para encontrarmos as respostas.

História não é bula de remédio nem produz efeitos rápidos de curta ou longa duração. Ajuda, porém, a tirar o véu do espanto e a produzir uma discussão mais crítica sobre nosso passado, nosso presente e o sonho de futuro. (SCHWARCZ, 2019, p. 26)

Snyder (2017) também defende a imprescindibilidade de recorrermos à história para tentar salvar a atual ordem política, pois ela tem o poder de familiarizar e de advertir. Para o autor norte-americano não podemos cair na armadilha de pensar que a nossa herança democrática nos protegeria automaticamente das ameaças autoritárias vindas de políticos ou partidos que supostamente representam a vontade popular, é preciso revisitar os acontecimentos e compreender as fontes da tirania para refletir sobre o que pode ser feito para impedi-la (SNYDER, 2017).

Na história brasileira, Schwarcz (2019) elenca o mandonismo, o patriarcalismo, o 
patrimonialismo, a escravidão, o racismo, a intolerância, a desigualdade e a violência como os elementos causadores da nossa tendência autoritária. Juntamente com a análise destas características, ainda fortemente presentes hoje, a autora busca desfazer alguns mitos que permeiam o nosso imaginário sobre o que significa ser brasileiro.

O primeiro deles é o de que seríamos um povo harmônico e sem conflitos; o segundo, de que o brasileiro seria avesso a qualquer forma de hierarquia, respondendo às adversidades com informalidade e igualdade; o terceiro, de que somos uma democracia plena, livre de racismo, preconceitos religiosos e de gênero; e, por fim, o quarto, de que o nosso país, nossa natureza e geografia são tão especiais que viveríamos num paraíso (SCHWARCZ, 2019). Quem já não ouviu o ditado que diz que Deus é brasileiro?

Voltando às características, o brasileiro é guiado por um excesso de intervencionismo do governo desde a chegada dos portugueses, é como se a nossa vida girasse em torno do governo (GARSCHAGEN, 2015). As interferências estatais criaram uma cultura de dependência e de submissão ao Estado que ultrapassa os limites da política e da economia e transborda para a esfera social.

Como nossa metrópole era distante, no Brasil colônia a subordinação ao governo era traduzida pela submissão, em primeiro lugar, à nobreza vinda de Portugal, que ocupava os cargos e funções importantes aproveitando todos os proventos do governo e, em segundo lugar, às famílias latifundiárias que assumiam a função de governo local e concentravam o poder político (SCHWARCZ, 2019).

Como nossa Constituição Federal, promulgada no ano de 1988 é complexa e ideológica ainda hoje, mesmo odiando os políticos com todas as nossas forças, preferimos relegar a política, da qual pouco entendemos, a uma pequena elite. (GARSCHAGEN, 2015). Esta elite personaliza as leis e as instituições em benefício próprio e usurpa o bem público na frente de todos, apropriando-se de tudo o que seja do governo. O patrimonialismo seria, portanto, a forma autoritária e personalista com que o brasileiro lida com o poder.

E se a elite, tão odiada, mas tão venerada, tira o máximo proveito e trata o público como se fosse privado, porque o brasileiro comum não agiria da mesma forma? A ideia de que o bem público é seu é intrínseca a todo o brasileiro. Acreditamos piamente que por pagar impostos e eleger os políticos tudo o que for do governo é nosso de direito, reforçando a ideia individualista com que lidamos com a política e a nossa carência de coletividade.

O hábito de furar filas, de levar vantagem em tudo e de resolver os problemas por meio de troca de favores é o reflexo da nossa mentalidade egoísta e personalista e, então, passamos a descrever outro grave problema brasileiro: a corrupção. Desde que éramos uma 
colônia de exploração composta por grandes propriedades latifundiárias sob o domínio frágil de uma metrópole distante buscamos maneira para burlar as regras e transgredir a lei em benefício próprio (SCHWARCZ, 2019).

Estamos tão acostumados com os escândalos políticos de corrupção e com o descaso com o dinheiro público que não nos damos conta que o governo perde eficiência quando os interesses públicos são desviados. A política torna-se inapta e ineficaz, a economia é afetada e apenas alguns poucos saem ganhando.

A corrupção, portanto, é fortemente disseminada no meio político para permitir a perpetuação no poder, reforçando os já citados mandonismo e patrimonialismo. Na realidade, todas essas características se alimentam e se reforçam e, para Schwarcz (2019), acentuam nossa tendência autoritária juntamente com o racismo e a intolerância.

Recebemos metade dos africanos escravos desembarcados nas Américas e ainda hoje somos um povo racista (SCHWARCZ, 2019). As demonstrações de intolerância, no entanto, não se resumem à raça, sendo hoje também de caráter religioso, sexual e político, tendo causado o aumento nos crimes contra todo tipo de minoria. Para Schwarcz (2019), o Brasil nunca será uma democracia plena enquanto toda a intolerância não for eliminada.

Por fim, a desigualdade social e a violência também fortaleceriam nossa tendência autoritária (SCHWARCZ, 2019). A desigualdade social, tão característica de países de passado colonial, é naturalizada no Brasil e perpetuou-se no setor econômico, regional, de gênero e de oportunidades. Nossas diferenças só não são maiores do que o nosso tamanho continental.

Mesmo depois de 130 anos da abolição da escravidão e 30 anos da promulgação da Constituição Federal de 1988 não conseguimos distribuir a riqueza e garantir oportunidades iguais para todos, ostentando o posto de nono país mais desigual do mundo de acordo com a Oxfam International (SCHWARCZ, 2019). Como as demais, esta característica está interligada com a corrupção, o mandonismo e o enraizamento das práticas patrimonialistas.

Para completar o cenário, vivemos uma epidemia de violência de acordo com a Organização Mundial de Saúde, temos uma das polícias que mais mata no mundo e nossas taxas de mortalidade são trinta vezes maiores do que as da Europa (SCHWARCZ, 2019). Nas grandes cidades sofremos nas mãos do crime organizado, do narcotráfico e das milícias, no campo, vivemos em meio à violência rural e ambiental. Tanta criminalidade gera uma sensação de impunidade e um ceticismo em relação aos agentes de segurança pública e ao governo. Cansados de viver com medo e buscando por um fim ao ciclo de violência endossamos políticos que prometem enfrentá-la com medidas igualmente violentas. 
Estes dados demonstram o quanto a nossa cidadania é precária, o quanto somos individualistas, revanchistas e segregadores. Para Schwarcz (2019) o que falta ao brasileiro é uma virtude cívica, um interesse pelo coletivo e pelos princípios próprios de uma vida pública. Não iremos progredir sem uma mudança de mentalidade e sem investimento na educação pública.

De fato foi comprovado que quanto menor o índice de escolaridade, maior a aposta em soluções autoritárias, pelo menos no Brasil. Este é um dos resultados obtidos na pesquisa "Medo da Violência e o Apoio ao Autoritarismo no Brasil - Índice de Propensão ao Apoio a Posições Autoritárias” realizada pelo Fórum Brasileiro de Segurança Pública (FBSP, 2017) que constatou, de forma empírica, que os brasileiros têm uma alta propensão a apoiar posições e ideias autoritárias.

A pesquisa foi realizada em 2017, entrevistando 2.087 brasileiros em 130 municípios de todas as regiões do Brasil e teve como base as afirmativas da Escala F, uma escala psicométrica desenvolvida pelo sociólogo alemão Theodor Adorno em conjunto com um grupo de psicólogos sociais da Universidade de Berkeley, na Califórnia, no pós Segunda Guerra Mundial para medir as tendências de crescimento do autoritarismo nos Estados Unidos (o "F" faz referência ao fascismo). Como nenhum entrevistado assumiria abertamente tendências anti-democráticas, as afirmativas da Escala $\mathrm{F}$ tem um cunho autoritário implícito e na realidade tratam de temas genéricos como família, comportamento e religião (FBSP, 2017).

Sabendo que a escala varia de 0 a 10 , sendo 10 uma forte propensão ao apoio às posições autoritárias, a nota média alcançada pelo brasileiro foi de 8,1. Considerando apenas os entrevistados que responderam "concordo" ou "concordo parcialmente", os resultados gerais da pesquisa foram os seguintes:

83\% concordam que não há nada pior do que uma pessoa que não sente profundo amor, gratidão e respeito por seus pais;

$81 \%$ concordam que a obediência e o respeito à autoridade são as principais virtudes que devemos ensinar as nossas crianças;

$69 \%$ concordam que o que este país necessita, principalmente, antes de leis ou planos políticos, é de alguns líderes valentes, incansáveis e dedicados em quem o povo possa depositar a sua fé;

$68 \%$ concordam que nenhuma pessoa decente, normal e em seu são juízo pensaria em ofender um amigo ou parente próximo;

$53 \%$ concordam que o policial é um guerreiro de Deus para impor a ordem e proteger as pessoas de bem;

$79 \%$ concordam que, hoje em dia, as pessoas se intrometem cada vez mais em assuntos que deveriam ser somente pessoais e privados; 
$77 \%$ concordam que se falássemos menos e trabalhássemos mais, todos estaríamos melhor;

69\% concordam que os crimes sexuais tais como o estupro ou ataques a crianças merecem mais que prisão; quem comete esses crimes deveria receber punição física publicamente ou receber um castigo pior;

$68 \%$ concordam que, às vezes, os jovens têm ideias rebeldes que, com os anos, deverão superar para acalmar os seus pensamentos;

$60 \%$ concordam que a maioria de nossos problemas sociais estaria resolvida se pudéssemos nos livrar das pessoas imorais, dos marginais e dos pervertidos;

$45 \%$ concordam que se deve castigar sempre todo insulto à nossa honra;

$13 \%$ concordam que os homossexuais são quase criminosos e deveriam receber um castigo severo;

$75 \%$ concordam que a ciência tem o seu lugar, mas há muitas coisas importantes que a mente humana jamais poderá compreender;

$64 \%$ concordam que todos devem ter fé absoluta em um poder sobrenatural, cujas decisões devemos acatar;

$54 \%$ concordam que um indivíduo de más maneiras, maus costumes e má educação dificilmente pode fazer amizade com pessoas decentes;

$44 \%$ concordam que os homens podem ser divididos em duas classes definidas: os fracos e os fortes; e

$31 \%$ concordam que a pobreza é consequência da falta de vontade de querer trabalhar. (FBSP, 2017, p.13)

Analisando os diferentes subgrupos da pesquisa nossa nota foi 8,08 em "submissão à autoridade" o que indicaria a receptividade de agir de acordo com o que dizem as autoridades sem questionamentos; 7,36 em "convencionalismo" que é a adesão rígida a valores convencionais da sociedade, o apego às normas morais e uma inclinação a punir quem não as segue, de uma forma também mensura a crença em causas externas fanáticas ou místicas que determinam o destino dos indivíduos; e 6,50 em "agressividade autoritária" que é a tendência a perseguir, condenar, rejeitar e punir (violentamente) as pessoas que violam os valores convencionais e tradicionais, mesmo que resulte em opressão (FBSP, 2017).

O Índice demonstrou que a tendência ao autoritarismo permeia toda a sociedade brasileira, variando apenas de acordo com os segmentos sociais analisados, por exemplo, quanto mais escolarizados e ricos, menos adeptos haverá a este tipo de posicionamento. Por outro lado, a população de 60 anos ou mais é a que tem maior adesão às tendências autoritárias, seguida - surpreendentemente - da faixa da população mais jovem, de 16 a 24 anos. O autoritarismo também é mais forte na população que se autodeclara preta e parda, em municípios pequenos com até 50 mil habitantes e nas regiões Nordeste e Sul (FBSP, 2017).

Por fim, a tendência autoritária é mais elevada nas pessoas que mais têm medo da violência, ou seja, é fruto da alta criminalidade no país. Segundo a pesquisa, vivemos amedrontados pela violência o que acaba fazendo com que recorramos a figuras fortes e 
radicais de liderança para resolver a questão e aceitemos punições violentas para os infratores. Enquanto não encararmos este drama e não construirmos um novo projeto político e institucional para a segurança pública do país, veremos tentações autoritárias crescerem e correremos sérios riscos de retrocessos civis, políticos, sociais e econômicos (FBSP, 2017, p.8).

Apesar de traçar apenas um perfil psicológico e não eleitoral do brasileiro, as tendências autoritárias constatadas podem muito bem ser refletidas no setor político e diante destas conclusões nos indagamos: se uma parte dos estudos internacionais sobre o tema aponta que cerca de um terço da população mundial tem pré-disposição a apoiar líderes autoritários (STENNER; HAIDT, 2018), enquanto outra defende que o autoritarismo é uma característica latente que se manifestaria apenas em momentos de crise (KAKKAR; SIVANATHAN, 2017), o que dizer dos brasileiros? Dobramos a meta? Vivemos uma crise constante? Nosso autoritarismo é menos latente? Nossa história é tão singular e específica que extrapolamos a média global das pesquisas?

O perfil psicológico analisado em conjunto com um contexto histórico e social nos mostrará que o autoritarismo no Brasil não pode ser simplesmente ativado ou desativado, ele vive entre nós. Se quisermos viver confortavelmente em uma democracia liberal moderna, temos muito para fazer. A mudança antes de acarretar na eleição de políticos comprometidos com os direitos fundamentais e com valores democráticos, passa por uma transformação da população brasileira e de suas características. Se é impossível modificar o passado, o futuro certamente é moldável.

Se alguns dos dados empíricos e dos porquês só agora se tornaram admitidos, as consequências das nossas escolhas e os seus efeitos nas nossas vidas nós já conhecíamos muito bem. Estamos onde estamos, submetidos a um governo de fortes características autoritárias, sujeitos à corrupção em todas as esferas da vida social, vivendo em meio a uma epidemia de violência, sendo uma população intolerante, desigual e preconceituosa ou porque o permitimos ou porque o queremos. De todas as formas, não podemos cair no conto de que haverá alguém para nos resgatar ou nos guiar em direção a um mundo melhor, este caminho deverá ser traçado por cada um de nós.

\section{Considerações finais}

De acordo com a análise histórica realizada por Schwarcz e diante dos dados levantados pelo Fórum Brasileiro de Segurança Pública, não podemos continuar acreditando 
que a onda autoritária que atingiu o Brasil é passageira. Não podemos culpar a globalização, a diversidade social ou a crise econômica pelo "inesperado" boom autoritário. Ao constatar que a história contribuiu para o desenvolvimento de tendências autoritárias nos brasileiros, comportamento constatado por uma pesquisa de campo, não podemos tratar o autoritarismo como um fenômeno novo ou pontual na vida do brasileiro.

Entusiastas da democracia e do multiculturalismo por vezes cometem o erro de acreditar que estávamos em um ponto iluminado da história da humanidade em que todos os indivíduos - independentemente de suas personalidades - estavam evoluindo de forma previsível e linear tornando-se cidadãos democráticos mais perfeitos (STENNER; HAIDT, 2018). É por isso que a "onda populista" atinge tantos observadores como uma loucura momentânea que "surgiu do nada" gatilhada por sentimentos de frustração e raiva que acarretam em obediência a líderes populistas irresponsáveis (STENNER; HAIDT, 2018).

Os dados nos mostram que o problema é bem mais profundo. $\mathrm{O}$ autoritarismo não é um devaneio transitório, mas uma característica constante das sociedades humanas. É um sentimento latente que espreita sob a superfície e pode ser ativado pelas próprias características que constituem a essência da democrática liberal, como a ampliação de direitos, a maior diversidade social e a economia globalizada (STENNER; HAIDT, 2018).

O comportamento autoritário é despertado pela interação entre uma pré-disposição psicológica e a intolerância à ameaça a ordem, neste caso, motivada pelo avanço da democracia liberal. Portanto, não há que se falar que existam mais pessoas com tendências autoritárias hoje, mas que existem mais situações que fazem com que estas tendências se manifestem (STENNER; HAIDT, 2018). Por esta mesma razão, não há como classificar o atual fenômeno como temporário que irá passar assim que recobrarmos a consciência ou a economia e a política melhorarem.

Se a corrupção, o racismo, o mandonismo, a intolerância e a violência são a causa da tendência autoritária no Brasil apenas se nos livrarmos de todos estes males é que conseguiremos abandoná-la. Se o autoritarismo brasileiro é menos latente do que em outros países e a nossa intolerância está tão presente hoje quanto estava no passado - como mudamos este cenário? Para Schwarcz (2019, p.230), "a resposta para a crise política, econômica, social e cultural [...] só virá de um projeto de nação mais inclusivo e igualitário. Apenas o investimento numa formação educacional sólida, ampla e equânime pode abalar o ceticismo que tomou a sociedade brasileira $[\ldots] "$ ".

Não estamos perpetuamente condenados ao domínio de um Estado intervencionista e de líderes autoritários em razão da nossa herança. Existem alternativas ao modelo político em 
vigor e cabe à população brasileira mudar a sua mentalidade para que as próximas páginas da história sejam mais brilhantes.

\section{Referências}

ADLER, David. Centrists are the most hostile to democracy, not extremists. The New York Times, Nova Iorque: 23 mai. 2018. Disponível em: https://www.nytimes.com/interactive/2018/05/23/opinion/international-world/centristsdemocracy.html. Acesso em: 30 mar. 2020.

CHALITA, Gabriel Benedito Issaac; LEVY, Wlson. DEMOCRACIA, COOPERAÇÃO E CIDADANIA. Revista Juridica, [S.1.], v. 4, n. 57, p. 422 - 441, fev. 2020. ISSN 2316-753X. Disponível em: $<$ http://revista.unicuritiba.edu.br/index.php/RevJur/article/view/3780/371372138>. Acesso em: 19 abr. 2020. doi:http://dx.doi.org/10.21902/revistajur.2316-753X.v4i57.3780.

DOBSON, William J. The Dictator's Learning Curve: Inside the Global Battle for Democracy. Nova Iorque: Anchor Books, 2013.

FÓRUM BRASILEIRO DE SEGURANÇA PÚBLICA - FBSP. Medo da Violência e o Apoio ao Autoritarismo no Brasil - Índice de Propensão ao Apoio a Posições Autoritárias. São Paulo: 2017. Disponível em: http://www.forumseguranca.org.br/wpcontent/uploads/2019/04/FBSP indice_propensao_apoio_posicoes_autoritarios_2017_relatori o.pdf. Acesso em: 20 jan. 2020.

GARSCHAGEN, Bruno. Para de acreditar no governo: por que os brasileiros não confiam nos políticos e amam o Estado. Rio de Janeiro: Record, 2015.

INSTITUT MONTAIGNE. What to do about neo-authoritarians? Ingredients to start a debate. Paris, 2018. Disponível em: https://www.institutmontaigne.org/en/blog/what-doabout-neo-authoritarians-ingredients-start-debate. Acesso em: 20 jan. 2020.

KAKKAR, Hermant; SIVANATHAN, Niro. When the appel of a dominant leader is greater than a prestige leader. Washington, 2017. Disponível em: https://www.pnas.org/content/114/26/6734. Acesso em: 10 fev. 2020.

LEVITSKY, Steven; ZIBLATT, Daniel. Como as democracias morrem. Tradução de Renato Aguiar. 1 ed. Rio de Janeiro: Zahar, 2018.

MOUNK, Yascha. O Povo Contra A Democracia: Por que nossa liberdade corre perigo e como salvá-la. Tradução de Cássio de Arantes Leite e Débora Landsberg. São Paulo: Companhia das Letras, 2019. E-book não paginado.

ROA, Fernanda Augusta de Vasconcelos. O avanço do populismo em democracias consolidadas. Monografia (Graduação em Direito) Pontifícia Universidade Católica de Minas Gerais, Belo Horizonte, 2017.

SCHWARCZ, Lilia Moritz. Sobre o Autoritarismo Brasileiro. São Paulo: Companhia das Letras, 2019. 
SNYDER, Timothy. Sobre a Tirania - Vinte lições do século XX para o presente. Tradução de Donaldson M. Garschagen. São Paulo: Companhia das Letras, 2017.

STENNER, Karen. The Authoritarian Dynamic (Cambridge Studies in Public Opinion and Political Psychology). Cambridge: Cambridge University Press, 2005.

STENNER, Karen; HAIDT, Jonathan. Authoritarianism is not a momentary madness, but an eternal dynamic within liberal democracies. In: SUNSTEIN, Cass R. Can it happen here? Authoritarianism in America. Nova Iorque: Harper Collins, 2018. p. 175-219.

THE ECONOMIST INTELLIGENCE UNIT. Democracy Index 2019 - A year of democratic setbacks and popular protest. Londres, 2020. Disponível em: https://www.eiu.com/topic/democracy-index. Acesso em: 28 jan. 2020. 